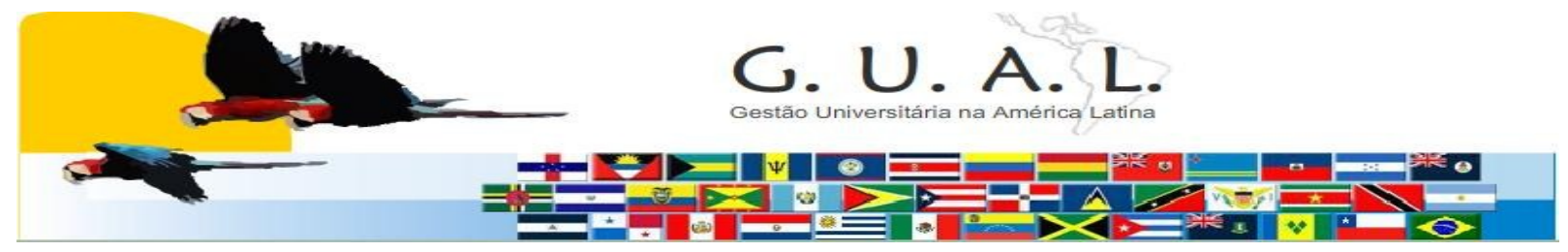

ISSN 1983-4535

\title{
PROJETO UAB: UMA ANÁLISE ESTRUTURAL DOS PÓLOS DE APOIO PRESENCIAL DO CURSO DE ADMINISTRAÇÃO DA UFSC
}

\author{
Daniele Weidle, Bacharel \\ Universidade Federal de Santa Catarina \\ daniele.weidle@gmail.com
}

Juliane Ines Di Francesco Kich, Mestre Universidade Federal de Santa Catarina julikich@gmail.com

Mauricio Fernandes Pereira, Doutor Universidade Federal de Santa Catarina mfpcris@gmail.com

\section{RESUMO}

A Educação a Distancia vem ocupando um importante espaço dentro da educação nacional, pois através dela tem-se proporcionado educação de qualidade em lugares carentes de ensino; assim proporcionando desenvolvimento para a região onde se encontram os polos de apoio presencial. Estes pólos são essenciais para o desenvolvimento dos cursos a distância, pois se constitui no local onde o aluno tem o apoio presencial, fornecido pela estrutura disponível laboratórios de informática, salas de aula e biblioteca - assim como os coordenadores e tutores presenciais, que incentivam e também auxiliam nas dúvidas dos alunos. Neste sentido, este trabalho dedica-se a analisar a estrutura de todos os polos de apoio presencial do projeto Universidade Aberta do Brasil (UAB), do curso de Administração da Universidade Federal de Santa Catarina, com base na estrutura mínima de polo presencial exigida pelo Ministério da Educação. Para tanto, foi aplicado um questionário quali-quantitativo em todos os polos, com questões direcionadas para fins deste estudo, oferecendo assim um panorama geral da situação estrutural do curso em questão. Percebeu-se que existem diferenças estruturais entre os polos do mesmo curso e projeto, sendo que todos apresentaram alguma carência diante da estrutura proposta pelo MEC.

Palavras-chave: Educação a distancia. Universidade aberta do Brasil. Polo de apoio presencial. Estrutura. 


\section{INTRODUÇÃO}

A modalidade de Ensino a Distância (EaD) tem se destacado no Brasil nos últimos anos, com um crescimento expressivo. Apesar de recente, já possui muitos adeptos. Segundo Moran (2011), uma das razões principais para esse crescimento seria a demanda reprimida de alunos não atendidos, principalmente por motivos econômicos. $\mathrm{O} \mathrm{EaD}$ tem uma longahistória, e uma de suas primeiras experiências, segundo Alves (1994), está datada em 1833 na Suécia. Mas seu crescimento no Brasil começou aparecer principalmente na década de 90 quando foi criada a Secretaria de Educação a Distância (SEED), através do Decreto $n^{\circ} 1.917$, de 27 de maio de 1996.

A partir do momento que a Instituição de Ensino Superior (IES) é aprovada pelo governo para oferecer determinados cursos, as prefeituras interessadas se candidatam para sediar um polo de apoio presencial. A qualidade de ensino é um dos quesitos principaise a qualidade da estrutura deve corresponder à necessidade da demanda. Entre os envolvidos no processo, a Universidade e o Polo de Ensino são os que estão ligados diretamente com os alunos. Ambos, ao entrarem no $\mathrm{EaD}$, se comprometem com uma série de requisitos exigidos pelo Ministério da Educação (MEC).

Desde que o EaD surgiu, procura-se encontrar normas e estruturas para que seja conduzido da melhor forma, alcançando os melhores resultados. Apesar do desenvolvimento desta modalidade de ensino, sabe-se que ainda há um caminho a ser percorrido para chegar-se ao ideal.

O projeto Universidade Aberta do Brasil (UAB) do curso de Administração da Universidade de Santa Catarina atende a 15 polos de apoio presencial nos estados do Rio Grande do Sul (Hulha Negra, Jacuizinho, São Francisco de Paula, Seberi, Tapejara e Tio Hugo), Paraná (Cidade Gaúcha, Cruzeiro do Oeste e Paranaguá), Bahia (Mata de São João) e Roraima (Boa Vista, Bonfim, Caroebe, Mucajaí e Uiramutã).

A prefeitura, juntamente com o polo, ao manifestar interesse na oferta do curso compromete-se em oferecer uma estrutura adequada aos alunos, no mínimo, a exigida pelo MEC, a qual deve manter-se no decorrer do curso.

Neste sentido, esse trabalho tem por objetivo analisar a estrutura dos polos do projeto Universidade Aberta do Brasil (UAB) do curso de Administração da Universidade Federal de 
Santa Catarina (UFSC), e averiguar se existe alguma inconformidade com os requisitos exigidos pelo MEC.

Para tanto será realizada uma pesquisa descritiva compesquisa bibliográfica e coleta de dados através de questionáriocom 8 questões quantitativas e 1 qualitativa, aplicado a todos os polos de apoio presencial do projeto UAB do curso de Administração da UFSC.

Esta pesquisa se mostra relevante ao passo que investigará os problemas enfrentados pelos polos, no que tange a estrutura destes, podendo assim contribuir para possíveis soluções para o melhoramento do atendimento dos seus objetivos.

Este trabalho oferecerá um panorama geral da situação estrutural de todos os polos do projeto UAB, curso de Administração da Universidade Federal de Santa Catarina.

\section{REFERENCIAL TEÓRICO}

\subsection{A história da EaD no Brasil}

A Educação a Distância é conceituada por diversos autores. Sua grande maioria traz a visão da educação de qualidade sendo levada a pessoas de difícil acesso, ou seja, expansão e popularização. Meireles (1999), conceitua EaD como sendo uma "estratégia desenvolvida por sistemas educativos para oferecer educação a setores ou grupos da população que, por razões diversas, têm dificuldade de acesso a serviços educativos regulares."

Segundo Neto e Brasileiro (2002, p. 11):

Ensino a Distância (EaD), inicialmente associado ao estudo por correspondência, foi criado para da oportunidade de estudo a todas as pessoas que, por razões financeiras, sociais, geográficas ou por incapacidade física, não podiam frequentar uma escola. Assim, o principal objetivo era facilitar o acesso à educação às pessoas que não tinha condições de obter instrução pelos métodos convencionais, pretendendo-se com isso aumentar o nível cultural das populações.

Para Aparici (1998), o desenvolvimento da EaD pode ser dividido em quatro etapas: 1) por correspondência; 2) analógica, caracterizada pela radiodifusão (rádio e televisão); 3) introdução da informática (CD's, rede de computadores) e 4) digital (internet, videoconferências), que possibilitou maior comunicação entre tutores e alunos.

Em cada país, a Educação a Distância se desenvolveu em diferentes épocas. No Brasil, foco deste estudo, foi em 1923 com a criação da Fundação da Rádio Sociedade do Rio de 
Janeiro, a qual transmitia programas de literatura, línguas, radiotelegrafia, entre outros. Em 1941, com a mídia impressa, o Instituto Universal Brasileiro oferecia cursos supletivos e profissionalizantes,(DALMAU, 2011).

Segundo DALMAU (2011), a EaD foi reconhecida legalmente como modalidade de educação pela Lei de Diretrizes e Bases da Educação (LDB), em 1971, válido apenas para cursos supletivos. Os cursos de nível superior iniciaram em 1994, mas foi em 1996, com o artigo 80 da LDB, que ocorreu o reconhecimento de todos os níveis de ensino na modalidade à distância.

A partir desse momento houve um crescimento significativo da $\mathrm{EaD}$, cujo objetivo principal é a democratização da educação de qualidade. Inicialmente, a maioria dos cursos oferecidos estava na área da educação. Em 2006, com a regulamentação da Universidade Aberta do Brasil, o primeiro curso de graduação ofertado foi o de Administração de Empresas. Em 2008, o MEC lançou o Programa Nacional de Formação em Administração Pública - PNAP, o qual oferece os cursos de bacharelado de Administração Pública e especialização Lato Sensu em Gestão Pública, Gestão PúblicaMunicipal e Gestão em Saúde, (CAPES, 2011).

\subsection{Universidade Aberta do Brasil - UAB}

Através do Decreto 5.800 de 8 de junho de 2006, foi regulamentado o Sistema da Universidade Aberta do Brasil - UAB, objetivando "o desenvolvimento da modalidade de educação a distância, com a finalidade de expandir e interiorizar a oferta de cursos e programas de educação superior no País". (UAB, 2011)

Um sistema articulado em nível nacional, entre as Instituições Federais de Ensino (IFE's) e as três esferas do governo (Distrito Federal, Estados, Municípios) e demais interessados, que "oferece cursos de nível superior para camadas da população que têm dificuldade de acesso à formação universitária, por meio do uso da metodologia da educação a distância". Além da oportunidade de ensino, incentiva o desenvolvimento econômico dessas regiões e evita a migração para cidades maiores,(UAB, 2011).

Os principais participantes do sistema UAB são as IFE's e os polos municipais de apoio presencial, estrutura onde as atividades presenciais dos cursos acontecem. Os primeiros cursos oferecidos dentro desse sistema provieram de publicação de editais. O primeiro edital 
ofertava apenas cursos de instituições federais de ensino,o segundo permitiu participação de instituições federais, estaduais e municipais. (UAB, 2011)

A Resolução/FNDE/CD/nº 044, de 29 de dezembro de 2006 dispõe sobre os agentes do Sistema UAB:

Art. $4^{\circ}$ São integrantes do Sistema UAB:

I - O Ministério da Educação, por intermédio da Secretaria de Educação Básica (SEB), da Secretaria de Educação Superior (SESu), da Secretaria de Educação Profissional e Tecnológica (SETEC), da Secretaria de Educação a Distância (SEED) e a Fundação Coordenação de Aperfeiçoamento de Pessoal de Nível Superior (CAPES) - responsáveis pela articulação e gestão do Sistema UAB [...]

II - O Fundo Nacional de Desenvolvimento da Educação - FNDE - órgão responsável pelo apoio financeiro em relação a:

a) efetuar a abertura das contas bancárias dos beneficiários e o pagamento mensal das bolsas de estudo e pesquisa no âmbito do Sistema UAB, depois de cumpridas pela SEED as obrigações estabelecidas nesta Resolução;

b) suspender o pagamento das bolsas sempre que ocorrerem situações que motivem ou justifiquem a medida, inclusive por solicitação dos integrantes do Sistema UAB.

III - As IES públicas vinculadas ao Sistema UAB [...]

IV - Estados e Municípios proponentes de polos de educação a distância, que serão responsáveis pela indicação de nomes de professores da rede pública de ensino que atendam aos requisitos da Lei 11.273/2006 para a função de coordenador de polo e de tutor presencial (FNDE, 2006).

\subsection{Polos}

O polo é a estrutura física, mantida pelo município e/ou pelo estado, que dispõem de salas de aula e laboratório de informática, onde os alunos participam de encontros e avaliações presenciais. O seu objetivo é proporcionar uma estrutura adequada para o atendimento dos alunos e demais envolvidos com o EaD. Fazem parte desta estrutura: computadores, biblioteca, sala de multimídia, sala de aula; enfim, o que for necessário para o desenvolvimento do curso. (UAB, 2011)

Segundo o UAB (2011)

os polos de apoio presencial são as unidades operacionais para o desenvolvimento descentralizado de atividades pedagógicas e administrativas relativas aos cursos e programas ofertados a distância pelas instituições públicas de ensino superior no âmbito do Sistema UAB.

Enquanto o polo cuida do atendimento presencial, a tutoria cuida do atendimento didático-pedagógico. Os tutores à distância, por estarem mais próximos aos professores, 
auxiliam com as dúvidas de conteúdo, administrativas e acompanham o desenvolvimento das atividades, bem como as suas correções, (UAB, 2011).

Os polos recebem recursos provenientes do Sistema UAB, por meio do FNDE, para custear as bolsas dos coordenadores e tutores. Os custos com a remuneração dos demais colaboradores e com a estruturação e organização necessárias para manter o funcionamento do polo de acordo com as orientações do Sistema UAB são de responsabilidade dos Municípios e Estado, considerados Mantenedores do polo, (UAB, 2011).

A avaliação feita pelo MEC é in loco, tendo por objetivo auxiliar o polo a melhorar a sua estrutura, portanto, não tem caráter punitivo. Este relatório da avaliação é encaminhado a CAPES para que sejam tomadas as providências necessárias. (UAB, 2011)

No que se refere à estrutura dos polos, o MEC propõe os itens mínimos necessários para o bom funcionamento dos mesmos em busca do alcance de seus objetivos, variando das necessidades de cada curso oferecido.

Abaixo, o quadro disponível no site da UAB (2011), apresenta a lista de mobiliários e equipamentos mínimos necessários a serem oferecidos pelo polo:

Quadro 1 Mobiliário e equipamentos mínimos de um Polo UAB

\begin{tabular}{|c|c|c|}
\hline Dependência & Mobiliário & Equipamentos \\
\hline \multirow{4}{*}{$\begin{array}{c}\text { Sala para Secretaria } \\
\text { Acadêmica }\end{array}$} & Mesa para computador & Computador com multimídia \\
\cline { 2 - 3 } & Mesa de escritório & Impressora a laser \\
\cline { 2 - 3 } & Armários com 02 portas & Aparelho de telefone e fax \\
\cline { 2 - 3 } & Arquivos de aço & Webcam \\
\cline { 2 - 3 } & Mesa para telefone e fax & No-break \\
\cline { 2 - 3 } & Mural & Linha telefônica com ramais \\
\hline \multirow{4}{*}{ Sala de Coordenação do Polo } & Cadeiras giratórias & Acesso à internet para o polo \\
\cline { 2 - 3 } & Mesa de escritório & Computador completo \\
\cline { 2 - 3 } & Cadeiras giratórias & Webcam \\
\cline { 2 - 3 } & Mesa para computador & Aparelho de telefone \\
\cline { 2 - 3 } & Armário com 02 portas & \\
\hline \multirow{4}{*}{ Sala de Tutores Presenciais } & Mesas de reunião p/04 pessoas & Computadores completos \\
\cline { 2 - 3 } & Cadeiras estofadas & Scanner \\
\cline { 2 - 3 } & Cadeiras com braço & Impressora \\
\cline { 2 - 3 } & Mesas de escritório & Aparelho de telefone \\
\hline
\end{tabular}

Rev. GUAL., Florianópolis, Edição especial 2011, p.94-114. 


\begin{tabular}{|c|c|c|}
\hline & $\begin{array}{c}\text { Mesa para impressora e } \\
\text { scanner }\end{array}$ & Webcam \\
\hline & Armários com 02 portas & \\
\hline \multirow{5}{*}{ Sala de Professores } & Mesa de reunião $\mathrm{p} / 10$ pessoas & \\
\hline & Cadeiras estofadas & \\
\hline & Armário com porta & \\
\hline & Mural & \\
\hline & Quadro branco & \\
\hline \multirow{5}{*}{ Sala de Aula Presencial } & Carteiras estofadas & \\
\hline & Quadro branco ou negro & \\
\hline & Mural & \\
\hline & Mesa para professor & \\
\hline & Cadeira estofada & \\
\hline \multirow{8}{*}{ Laboratório de Informática } & Cadeiras estofadas & Computadores completos \\
\hline & Mesas para computador & Webcam \\
\hline & Quadro branco & Impressora e 01 scanner \\
\hline & Murais com vidro & Projetor multimídia \\
\hline & Mesa para projetor & Aparelho de TV 29" e DVD \\
\hline & Armários de segurança & Servidor \\
\hline & $\begin{array}{c}\text { Mesa para impressora e } \\
\text { scanner }\end{array}$ & No break, HUB e roteador \\
\hline & Suporte para TV & $\begin{array}{l}\text { Aparelhos de ar } \\
\text { condicionado }\end{array}$ \\
\hline \multirow{9}{*}{ Biblioteca } & Mesas p/04 pessoas & Computadores completos \\
\hline & Cadeiras estofadas & Aparelho de telefone \\
\hline & Cadeiras giratórias & Impressora \\
\hline & Mesas para computador & \\
\hline & Mesa de escritório & \\
\hline & Armários com fechaduras & \\
\hline & Mesa para impressora & \\
\hline & Armário com 02 portas & \\
\hline & Estantes de aço & \\
\hline
\end{tabular}

Fonte: UAB, 2011

O tamanho da estrutura dependerá da quantidade de cursos e de alunos que o polo abrigará. Além da estrutura física, o MEC estabelece também o quadro mínimo de colaboradores do polo de apoio presencial, para que as atividades sejam bem desenvolvidas. A UAB oferece bolsas para os coordenadores do polo e aos tutores presenciais, os demais são mantidos pelo próprio polo. 
Quadro 2 Recursos Humanos mínimos em um polo UAB

\section{Recursos Humanos}

Coordenador de Polo: responsável pela parte administrativa e pela gestão acadêmica

Tutor Presencial

Técnico de laboratório pedagógico, quando for o caso.

Técnico em Informática

Bibliotecária

Auxiliar para Secretaria

Fonte: UAB, 2011

\section{RESULTADOS DA PESQUISA}

Diante dos resultados obtidos através das análises das questões respondidas por todos os polos de apoio presencial do projeto UAB do curso de Administração da UFSC - Hulha Negra/RS, Jacuizinho/RS, São Francisco de Paula/RS, Seberi/RS, Tapejara/RS, Tio Hugo/RS, Cidade Gaúcha/PR, Cruzeiro do Oeste/PR, Paranaguá/PR, Mata de São João/BA, Boa Vista/RR, Bonfim/RR, Caroebe/RR, Mucajaí/RR e Uiramutã/RR - pode-se afirmar que existem diferenças nas estruturas entres eles.

Os itens de estrutura física exigidos pelo MEC são salas para: secretaria acadêmica, coordenador de polo, tutores presenciais, professores, aula presencial, laboratório de informática e biblioteca. Dentro destes, existem os itens de mobília e equipamentos: carteiras estofadas, mesas para computadores e scanner, cadeiras estofadas, cadeiras giratórias, armários, murais, quadros, computadores, webcam, etc. Além de exigirtambém, um quadro mínimo de colaboradores.

Abaixo, os quadros com o resultado dos itens que os polos possuem ou não, em suas respectivas salas. O primeiro refere-se à mobília, e o segundo, aos equipamentos. A legenda a seguir refere-se aos quadros 1,2 e 3 .

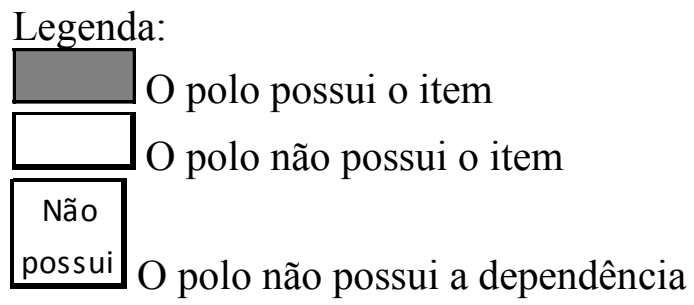


PROJETO UAB: UMA ANÁLISE ESTRUTURAL DOS PÓLOS DE APOIO PRESENCIAL DO CURSO DE ADMINISTRAÇÃO DA UFSC

\begin{tabular}{|c|c|c|c|c|c|c|c|c|c|c|c|c|c|c|c|c|}
\hline & \multirow[b]{2}{*}{ Mobiliário } & \multicolumn{15}{|c|}{ Polos UAB - Administração - UFSC } \\
\hline Dependência & & $\begin{array}{l}\text { Boa } \\
\text { Vista }\end{array}$ & Bonfim & Caroebe & Mucajai & Uiramutã & $\begin{array}{l}\text { Mata de } \\
\text { São João }\end{array}$ & \begin{tabular}{|l|} 
Cidade \\
Gaúcha
\end{tabular} & \begin{tabular}{|l|l} 
Cruzeiro \\
do Oeste
\end{tabular} & Paranaguá & \begin{tabular}{|l|} 
Hulha \\
Negra \\
\end{tabular} & Jacuizinho & $\begin{array}{c}\text { são Francisco } \\
\text { de Paula }\end{array}$ & Seberi & Tapejara & Tio Hugo \\
\hline \multirow{5}{*}{ Sala para Secretaria Acadêmica } & Mesa para computador & \multirow{5}{*}{$\begin{array}{c}\text { Não } \\
\text { possui }\end{array}$} & \multirow{5}{*}{$\begin{array}{c}\text { Não } \\
\text { possui }\end{array}$} & & \multirow{5}{*}{\begin{tabular}{|c|} 
Não \\
possui
\end{tabular}} & \multirow{5}{*}{$\begin{array}{c}\text { Não } \\
\text { possui }\end{array}$} & \multirow{5}{*}{$\begin{array}{l}\text { Não } \\
\text { possui }\end{array}$} & & & & & & & & & \\
\hline & Mesa para impressora e scanner & & & & & & & & & & & & & & & \\
\hline & Armários com 02 portas & & & & & & & & & & & & & & & \\
\hline & Arquivos de aço & & & & & & & & & & & & & & & \\
\hline & Mesa para telefone e fax & & & & & & & & & & & & & & & \\
\hline \multirow{5}{*}{ Sala de Coordenação do Polo } & Mesa de escritório & & & & & & & & & & & & & & & \\
\hline & Cadeiras giratórias & & & & & & & & & & & & & & & \\
\hline & Mural & & & & & & & & & & & & & & & \\
\hline & Mesa para computador & & & & & & & & & & & & & & & \\
\hline & Armário com 02 portas & & & & & & & & & & & & & & & \\
\hline & Mesas de reunião $\mathrm{p} / 04$ pessoas & & & & & & & & & & & & & & & \\
\hline & Cadeiras estofadas & & & & & & & & & & & & & & & \\
\hline & Cadeiras estofadas & Não & Não & & Não & Não & & Não & Não & Não & Não & Não & Não & Não & Não & Não \\
\hline Sala de Professores & Armário com porta & possui & possui & & possui & possui & & possui & possui & possui & possui & possui & possui & possui & possui & possui \\
\hline & Mural & & & & & & & & & & & & & & & \\
\hline & Quadro branco & & & & & & & & & & & & & & & \\
\hline & Carteiras estofadas & & & & & & & & & & & & & & & \\
\hline & Quadro branco ou negro & Não & & & & & & & & & & & & & & \\
\hline Sala de Aula Presencial & Mural & possui & & & & & & & & & & & & & & \\
\hline & Mesa para professor & & & & & & & & & & & & & & & \\
\hline & Cadeira estofada & & & & & & & & & & & & & & & \\
\hline
\end{tabular}

Rev. GUAL., Florianópolis, Edição especial 2011, p.94-114. 
PROJETO UAB: UMA ANÁLISE ESTRUTURAL DOS PÓLOS DE APOIO PRESENCIAL DO CURSO DE ADMINISTRAÇÃO DA UFSC

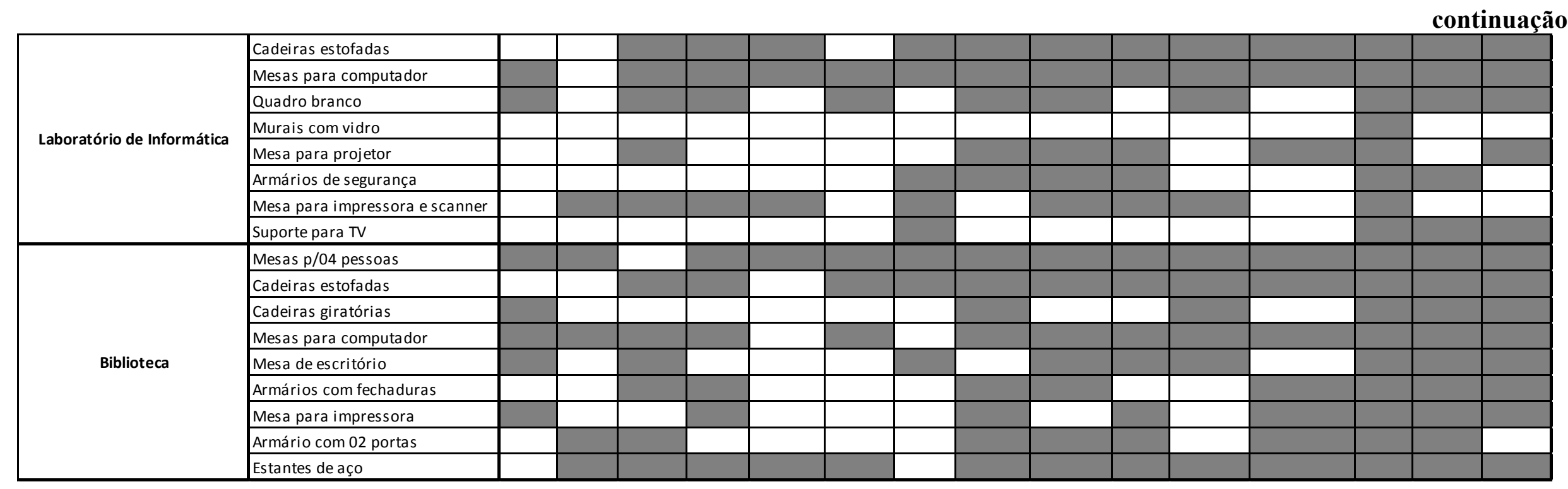

Quadro 3 Itens de Mobília 
PROJETO UAB: UMA ANÁLISE ESTRUTURAL DOS PÓLOS DE APOIO PRESENCIAL DO CURSO DE ADMINISTRAÇÃO DA UFSC

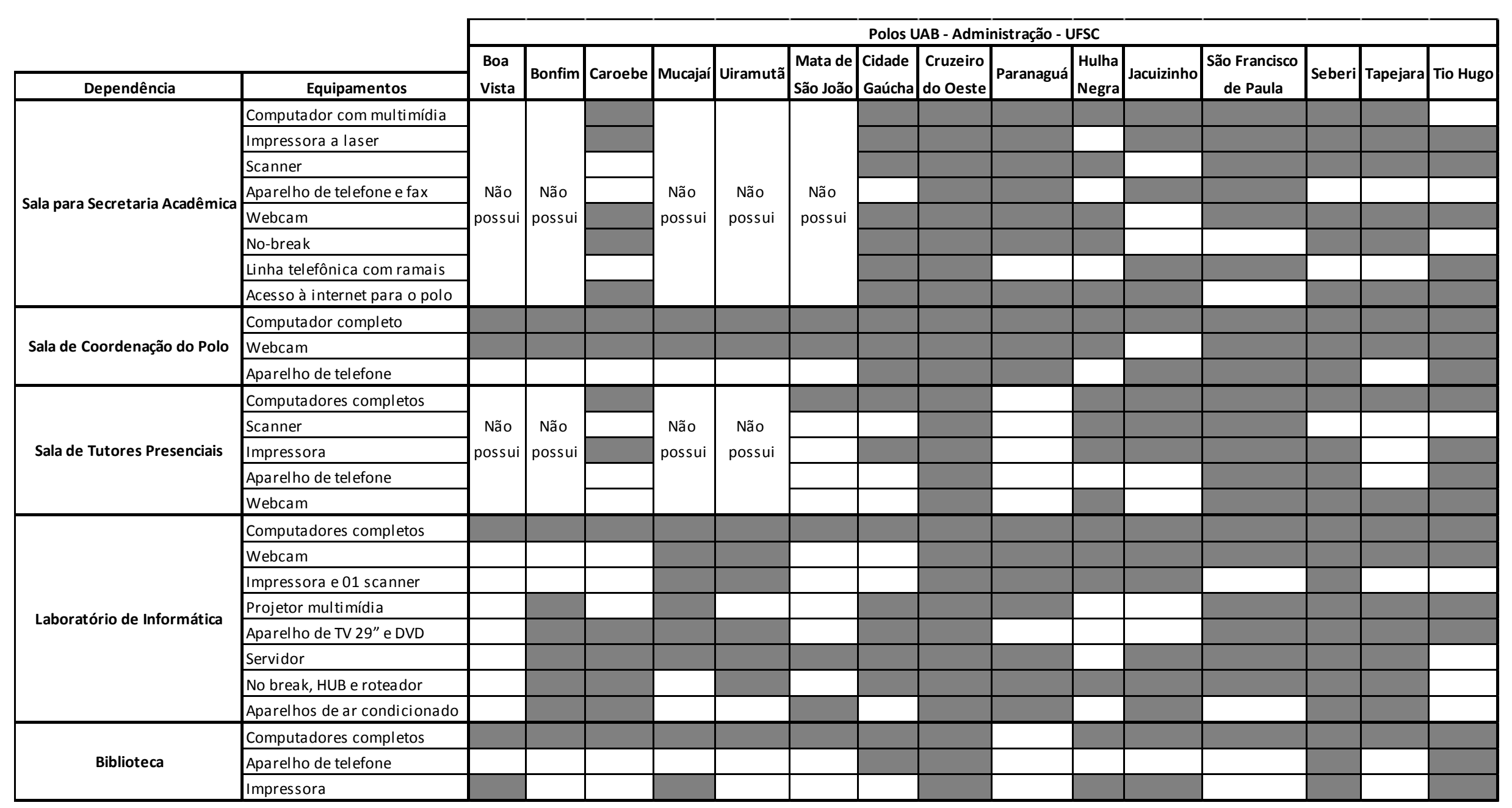

Quadro 4 Equipamentos

Rev. GUAL., Florianópolis, Edição especial 2011, p.94-114. 
A secretaria acadêmica não é privilégio de todos. Dos 15 respondentes, 10 possuem estrutura e 5 não possuem. Destes 5, 4 são polos de Roraima e 1 da Bahia. Os demais se encontram no Rio Grande do Sul e Paraná. Dos 10 polos que possuem a sala para a secretaria acadêmica, apenas 1 tem todos os itens de mobília e equipamentos completos, nos demais falta pelo menos 1 item. Entre os faltantes, a maior incidência está na mesa e aparelhos de telefone e fax, bem como a linha telefônica com ramais.

No que se refere à sala para o coordenador do polo, todos os pesquisados possuem. $\mathrm{O}$ que difere são os itens de mobília e equipamentos, onde apenas 4polos estão completos. Os únicos itens unânimes são a mesa para computador e o computador. Nos demais polos, o aparelho de telefone é a maior carência.

A sala dos tutores presenciais foi encontrada em 10 polos, dos quais, apenas 1 possui a estrutura de mobília e equipamentos completa. Nos demais, a principal falta está nos aparelhos de telefone, cadeiras com braço e scanner.

Quanto à sala de professores, percebe-se que esse item foi preenchido por polos que tem suas sedes em escolas. Apenas 2 polos possuem esta sala, os demais, não possuem. Destes 2, apenas 1 possui a mobília completa, o outro não tem mural nem mesa para reunião.

A sala de aula presencial, lugar onde as provas e encontros presenciais ocorrem, apenas 1 polo manifestou a carência. Os demais, todo possuem. Dos 14 polos, apenas 3 possuem a mobília completa. Os itens de maior falta são os murais e as carteiras estofadas.

Todos os polos possuem o laboratório de informática. Da mobíliae equipamentos exigidos, apenas um polo está completo.Os demais têm no mínimo 3 itens faltantes. Murais com vidro, mesa para projetor, armários de segurança, suporte para TV, aparelhos de ar condicionado, impressora, scanner e projetor multimídia são as principais faltas encontradas nos polos.

A biblioteca foi outra unanimidade. Porém, apenas 1 polo possui toda mobília e equipamentos citados; entre as maiores carências estão a impressora, o aparelho de telefone, os armários e as cadeiras giratórias.

Pode-se perceber, dentro dos itens de mobília e equipamentos, que o essencial está sendo cumprido pelos polos. Mas ainda existem muitas carências que prejudicam o andamento das atividades dos mesmos. A cobrança nessas questões deve ser dirigida aos mantenedores dos polos. 
Quanto à estrutura de Recursos Humanos dos polos, segue o quadro abaixo:

\begin{tabular}{|c|c|c|c|c|c|c|}
\hline \multirow[b]{2}{*}{ Pol } & \multicolumn{6}{|c|}{ Estrutura de Recursos Humanos } \\
\hline & $\begin{array}{c}\text { Coordenador } \\
\text { de Polo }\end{array}$ & $\begin{array}{c}\text { Tutor } \\
\text { Presencial }\end{array}$ & $\begin{array}{c}\text { Técnico de laboratório } \\
\text { pedagógico }\end{array}$ & $\begin{array}{c}\text { Técnico } \\
\text { em Informática }\end{array}$ & Bibliotecária & $\begin{array}{c}\text { Auxiliar } \\
\text { para Secretaria }\end{array}$ \\
\hline \multicolumn{7}{|c|}{ Boa Vista } \\
\hline \multicolumn{7}{|l|}{ Bonfim } \\
\hline \multicolumn{7}{|l|}{ Caroebe } \\
\hline \multicolumn{7}{|l|}{ Mucajaí } \\
\hline \multicolumn{7}{|c|}{ Uiramutã } \\
\hline \multicolumn{7}{|c|}{ Mata de São João } \\
\hline \multicolumn{7}{|c|}{ Cidade Gaúcha } \\
\hline \multicolumn{7}{|c|}{ Cruzeiro do Oeste } \\
\hline \multicolumn{7}{|c|}{ Paranaguá } \\
\hline \multicolumn{7}{|c|}{ Hulha Negra } \\
\hline \multicolumn{7}{|c|}{ Jacuizinho } \\
\hline \multicolumn{7}{|c|}{ São Francisco de Paula } \\
\hline \multicolumn{7}{|l|}{ Seberi } \\
\hline \multicolumn{7}{|l|}{ Tapejara } \\
\hline Tio Hugo & & & & & & \\
\hline
\end{tabular}

O quadro de coordenadores de polo e tutores presenciais está completo em todos os polos. Do total, 8 possuem técnicos de informática, sendo todos nos estados da Bahia, Rio Grande do Sul e Paraná. Nenhum polo de Roraima possui essa vaga preenchida.Já o bibliotecário é encontrado em 9 polos, compreendendo todos estados, exceto a Bahia. $\mathrm{O}$ auxiliar para a secretaria também é registrado em 9 polos. E quanto ao técnico de laboratório pedagógico, nenhum polo possui, pois nãose faz necessário ao curso de administração.

Ao perguntar aos polos sobre a saciedade das necessidades do público (estudantes e colaboradores), além das respostas sobre falta de estrutura física (itens de mobília e equipamentos), surgiram outros pontos importantes a serem observados. Entre eles a dificuldade de conexão a internet nos polos de Roraima e problemas na conexão das videoconferências por alguns polos .

Outra situação é o aumento de oferta de cursos/turmas pelos polos, oque acarreta no aumento de alunos. Este é um fato positivo para o polo e região, porém quando há mais cursos que o polo suporta fisicamente, dificulta o aproveitamento de cada curso. Por exemplo: um polo se propôs a ofertar 4 cursos; no andamento dos mesmos, eles são ofertados novamente em novas turmas, passando a ser 8 turmas. Toda a estrutura deveria acompanhar 
esse crescimento proporcionalmente, porém isto não ocorre, causando assim a superlotação do polo, trazendo dificuldades com a disponibilidade de equipamentos, os espaços de salas sejam de aula, informática e até mesmo biblioteca.

Por mais que os polos atendam as principais necessidades dos alunos e colaboradores, segundo a sua região, a discrepância entre polos de um mesmo projeto é muito grande. São condições muito diferentes para alunos de um mesmo curso.

\section{CONCLUSÃO}

A organização de um curso de Ensino a Distância depende da sincronia entre governo (recursos), universidade e polos. O governo dispõe do subsídio para manter a "máquina" funcionando. A universidade cuidará da organização, planejamento do curso, incluindo material, professores, profissionais, ambiente virtual. Para o bom funcionamento do curso no polo é necessário que os recursos estejam sincronizados com as necessidades do aluno.

Os polos de apoio presencial do projeto UAB do curso de Administração da UFSC estão localizados em regiões diferentes. Apesar de tentar proporcionar uma igualdade entre os alunos de um mesmo curso, é difícil conseguir atingir lugares tão diferentes da mesma forma, com a mesma estratégia, com a mesma estrutura.

A educação a distância, dentro de sua proposta de levar o ensino a todo e qualquer lugar, está suscetível a diferenças culturais e políticas e embora seja visível o compromisso dos coordenadores de polo com a gestão do mesmo, os mantenedores não se mostram da mesma forma. Fato comprovado com a diferença entre os polos analisados, onde os estados do Rio Grande do Sul e Paraná trouxeram uma estrutura mais completado que os demais.

Todos os polos possuem o laboratório de informática, afinal ele é um dos pontos mais importantes para um curso na modalidade de $\mathrm{EaD}$, a partir do momento que muitos alunos dependem dele para suprir suas dificuldades de acesso à internet. Quanto à sala de professores, apesar de ser exigência do MEC, não é uma necessidade do polo, uma vez que os professores encontram-se na universidade, longe dos mesmos.

Os tutores presenciais e os coordenadores, dentro de suas possibilidades, desenvolvem suas atividades de maneira satisfatória. A partir do momento que falta uma 
mobília ou um equipamento, o desempenho de suas tarefas fica comprometido, e o suprimento da necessidade do aluno, não atendido.

Além dos tutores e coordenadores, os técnicos de informática, os auxiliares de secretaria e bibliotecários são importantes para o desempenho das atividades do polo. Eles são a equipe de staff. A falta de algum deles acarreta no aumento do trabalho de outro, bem como a falta de resolução de determinados problemas pertinentes àquela função.

Ao constatar as carências do polo, há a necessidade de buscar maneiras de supri-las. Dentro dos itens necessários, segundo o $\mathrm{MEC}$, existem alguns que não são de suma importância ao andamento das atividades do polo, um exemplo é a cadeira giratória. Por isso é possível sugerir uma revisão dos itens de mobília e equipamentos, a fím de excluir o que não se faz necessário, e acrescentar itens de maior importância. Afinal, hipoteticamente, de nada adianta ter cadeiras estofadas, se o equipamento de multimídia não funciona como deveria.

Diante da disparidade social e econômica entre as regiões do país, precisa-se pensar em algo que possa ser operacionalizado em qualquer lugar, no que tange à estrutura mínima. $\mathrm{O}$ acesso à educação, a tecnologias é diferente em cada região. O polo que tiver condições de expandir, melhorar sua estrutura, poderá fazê-lo. No entanto, o polo que não tiver condições para tal, pelo menos terá o mínimo exigido, podendo assim, atender os alunos de forma completa. Uma ideia interessante seria especificar e quantificar a estrutura por curso, senão teremos polos oferecendo inúmeros cursos, com estrutura para no máximo 2 ou 3.

Em virtude da complexidade e extensão do tema é interessante que outras pesquisas específicas sejam realizadas, buscando analisar os motivos relacionados aos problemas enfrentados pelos polos, para que seja possível solucioná-los, trazendo assim maior eficiência aos processos da EaD.

\section{REFERÊNCIAS}

ALVES, JRM. A educação a distância no Brasil: síntese histórica e perspectivas. Rio de Janeiro: Instituto de Pesquisas Avançadas em Educação: Ipae. 1994.

APARACI, R. Mitos de La Educación a Distancia Y Las Nuevas Tecnologías. In: APARICI, R.; OSUNA, S. (Coord.). CD - ROM Recursos, versíon 1.0. Madrid: UNED, 1998.

CAPES. Coordenação de Aperfeiçoamento de Pessoal de Nível Superior. Disponível em: http://www.capes.gov.br. Acesso em: mar. 2011 
DALMAU, Marcos Baptista Lopez. Introdução à Educação a Distância. Florianópolis: UFSC, 2011.

FNDE. Estabelece orientações e diretrizes para a concessão de bolsas de estudo e de pesquisa a participantes dos cursos e programas de formação superior, no âmbito do Sistema Universidade Aberta do Brasil, vinculado ao Ministério da Educação, a ser executado pelo FNDE no exercício de 2006. Resolução n. 044, de 29 de dezembro de 2006. Disponível em: $<$ http://www.fnde.gov.br/index.php/leg-res-2006>. Acesso em: abr. 2011.

MEIRELES, Almir José. A rodada do milênio da OMC: como culpar o resto domundo pelas nossas mazelas. Balde Branco. São Paulo: v.36 , n.422 , p. 56-59,dez. 1999

MORAN, José Manuel. Avaliação do Ensino Superior a Distância no Brasil. Disponível em: http://www.eca.usp.br/prof/moran/avaliacao.htm. Acesso em: mar. 2011

NETO, F. M. M.; BRASILEIRO, F. V., Uma Taxonomia para Ambientes de Aprendizagem Suportados pela Web, Anais do XXII CSBC, 2002.

PORTAL UAB. Disponível em: http://www.uab.capes.gov.br. Acesso em: mar. 2011.

\section{BILIOGRAFIA CONSULTADA}

ALVES, JRM. A educação a distância no Brasil: síntese histórica e perspectivas. Rio de Janeiro: Instituto de Pesquisas Avançadas em Educação: IPEA. 1994.

APARACI, R. Mitos de La Educación a Distancia Y Las Nuevas Tecnologías. In: APARICI, R.; OSUNA, S. (Coord.). CD - ROM Recursos, versíon 1.0. Madrid: UNED, 1998.

ABED. Associação Brasileira de Educação a Distância - Disponível em: Http://www.abed.org.br/. Acesso em: mai. 2011

BRASIL. Congresso Nacional. Decreto $\mathrm{n}^{\circ}$ 1.917, de 27 de maio de 1996. Aprova a estrutura regimental e o quadro demonstrativo dos cargos em comissão e funções gratificadas do Ministério da Educação e do desporto e da outras providencias. Diário Oficial da União, Brasília, DF, 28 mai. 1996.

BRASIL. Congresso Nacional.Lei $n^{\circ}$ 9.394, de 20 de dezembro de 1996. Estabelece as diretrizes e bases da educação nacional. Diário Oficial da União, Brasília, DF, 20 dez. 1996.

BRASIL. Congresso Nacional. Decreto-Lei n ${ }^{\circ}$ 5.800, de 8 de junho de 2006. Dispõe sobre o Sistema Universidade Aberta do Brasil - UAB. Diário Oficial da União, Brasília, DF, 9 jun. 2006.

CAPES. Coordenação de Aperfeiçoamento de Pessoal de Nível Superior. Disponível em: http://www.capes.gov.br. Acesso em: mar. 2011 
DALMAU, Marcos Baptista Lopez. Introdução à Educação a Distância. Florianópolis: UFSC, 2011.

DOBES, Cantalícia E. I. Educação Superior a Distância: Uma experiência da Universidade Federal de Santa Catarina. Disponível em: http://rapes.unsl.edu.ar/Congresos_realizados /Congresos/III\%20Encuentro/Completos/IBARRA.pdf. Acesso em: mai. $201 \overline{1}$

FNDE. Fundo Nacional de Desenvolvimento da Educação. Estabelece orientações e diretrizes para a concessão de bolsas de estudo e de pesquisa a participantes dos cursos e programas de formação superior, no âmbito do Sistema Universidade Aberta do Brasil, vinculado ao Ministério da Educação, a ser executado pelo FNDE no exercício de 2006. Resolução n. 044, de 29 de dezembro de 2006. Disponível em: < http://www.fnde.gov.br/index.php/leg-res2006>. Acesso em: abr. 2011.

IRIONDO, Walter; RIBEIRO, Luciano. Gestão de Recursos Humanos no Contexto do Polo EaD. Universidade Federal de Pelotas, 2010.

MEGIATO, E. et al.Introdução ao Financiamento da Educação. Apostila do curso de Especialização em Gestão de Polos da UAB/UFPel, Pelotas, 2010.

. MEGIATO, E. et al. Fontes de Financiamento da Educação. Apostila do curso de Especialização em Gestão de Polos da UAB/UFPel, Pelotas, 2010.

MEIRELES, Almir José. A rodada do milênio da OMC: como culpar o resto domundo pelas nossas mazelas. Balde Branco. São Paulo: v.36 , n.422, p. 56-59,dez. 1999

Ministério da Educação. Disponível em: http://www.mec.gov.br Acesso em: abr. 2011

MORAN, José Manuel. Avaliação do Ensino Superior a Distância no Brasil. Disponível em: http://www.eca.usp.br/prof/moran/avaliacao.htm. Acesso em: mar. 2011

NETO, F. M. M.; BRASILEIRO, F. V., Uma Taxonomia para Ambientes de Aprendizagem Suportados pela Web, Anais do XXII CSBC, 2002.

PORTAL UAB. Disponível em: http://www.uab.capes.gov.br. Acesso em: mar. 2011 SEED. Secretaria de Educação a Distância- Disponível em:

http://www.mec.gov.br/seed/home.shtm. Acesso em: abr. 2011. 


\section{ANEXO \\ QUESTIONÁRIO}

Este questionário visaanalisar a estrutura dos polos de apoio presencial do projeto UAB, curso de Administração da Universidade Federal de Santa Catarina, em relação à pretendida pelo MEC.

Polo:

1. O polo possui uma sala para a Secretaria Acadêmica?

( ) $\operatorname{Sim}$ ( ) Não

Se a resposta foi sim, assinale dentre os itens abaixo, quais que o polo possui nessa sala:

\section{Mobília}

( ) mesa para computador

( ) mesa de escritório

( ) mesa para impressora e scanner

( ) armários com 02 portas

( ) arquivos de aço

( ) mesa para telefone e fax

( ) mural

( ) cadeiras giratórias

\section{Equipamentos}

( ) computador com multimídia

( ) impressora a laser

( ) scanner

( ) aparelho de telefone e fax

( ) webcam

( ) no-break

( ) linha telefônica com ramais

( ) acesso a internet para o polo

2. O polo possui uma sala para a Coordenação do polo?

( ) $\operatorname{Sim}$ ( ) Não

Se a resposta foi sim, assinale dentre os itens abaixo, quais que o polo possui nessa sala:

\section{Mobília}

( ) mesa de escritório

( ) cadeiras giratórias

( ) mural

( ) mesa para computador

( ) armário com 02 portas

\section{O polo possui sala para os tutores presenciais?}

( ) $\operatorname{Sim}$ ( ) Não

Se a resposta foi sim, assinale dentre os itens abaixo, quais que o polo possui nessa sala:

\section{Equipamentos}

( ) computador completo

( ) webcam

( ) aparelho de telefone 


\section{Mobília}

( ) mesas de reunião $\mathrm{p} / 04$ pessoas

( ) cadeiras estofadas

( ) cadeiras com braço

( ) mesas de escritório

( ) mesa para impressora e scanner

( ) armários com 02 portas

\section{Equipamentos}

( ) computadores completos

( ) scanner

( ) impressora

( ) aparelho de telefone

( ) webcam

\section{O polo possui sala de professores?}
( ) $\mathrm{Sim}$
( ) Não

Se a resposta foi sim, assinale dentre os itens abaixo, quais que o polo possui nessa sala:

\section{Mobília}

( ) mesa de reunião $\mathrm{p} / 10$ pessoas

( ) cadeiras estofadas

( ) armário com porta

( ) mural

( ) quadro branco

\section{O polo possui sala de aula presencial?}
( ) $\mathrm{Sim}$
( ) Não

Se a resposta foi sim, assinale dentre os itens abaixo, quais que o polo possui nessa sala:

\section{Mobília}
( ) carteiras estofadas
( ) quadro branco ou negro
( ) mural
( ) mesa para professor
( ) cadeira estofada

\section{O polo possui laboratório de informática?}

( ) Sim ( ) Não

Se a resposta foi sim, assinale dentre os itens abaixo, quais que o polo possui nessa sala:

\section{Mobília}
( ) cadeiras estofadas
( ) mesas para computador
( ) quadro branco
( ) murais com vidro
( ) mesa para projetor
( ) armários de segurança
( ) mesa para impressora e scanner
( ) suporte para TV

\section{Equipamentos}

( ) computadores completos

( ) Webcam

( ) impressora e 01 scanner

( ) projetor multimídia

( ) aparelho de TV 29" e DVD

( ) Servidor

( ) no break, HUB e roteador

( ) aparelhos de ar condicionado 


\section{O polo possui biblioteca?}
( ) $\mathrm{Sim}$
( ) Não

Se a resposta foi sim, assinale dentre os itens abaixo, quais que o polo possui nessa sala:

\section{Mobília}
( ) mesas $\mathrm{p} / 04$ pessoas
( ) cadeiras estofadas
( ) cadeiras giratórias
( ) mesas para computador
( ) mesa de escritório
( ) armários com fechaduras
( ) mesa para impressora
( ) armário com 02 portas
( ) estantes de aço

\section{Equipamentos}

( ) computadores completos

( ) aparelho de telefone

( ) impressora

\section{Na estrutura de RH do polo, assinale abaixo os cargos preenchidos no polo:}

( ) Coordenador de Polo

( ) Tutor Presencial

( ) Técnico de laboratório pedagógico, quando for o caso

( ) Técnico em Informática

( ) Bibliotecária

( ) Auxiliar para Secretaria

9. O polo, com a estrutura atual, atende as necessidades dos envolvidos? Caso a resposta seja negativa, o que falta para que isso ocorra? 


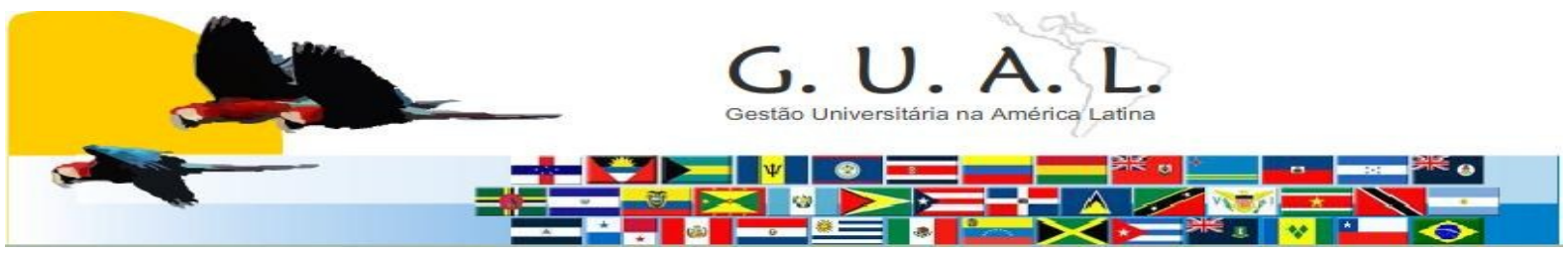

ISSN 1983-4535

\title{
UAB PROJECT: A STRUCTURAL ANALYSIS OF THE PRESENCE POLES SUPPORTING THE COURSE OF MANAGEMENT UFSC
}

\author{
Daniele Weidle, Bachelor \\ Universidade Federal de Santa Catarina \\ daniele.weidle@gmail.com \\ Juliane Ines Di Francesco Kich, Master \\ Universidade Federal de Santa Catarina \\ julikich@gmail.com \\ Mauricio Fernandes Pereira, Doctor \\ Universidade Federal de Santa Catarina \\ mfpcris@gmail.com
}

\begin{abstract}
The Distance Education has occupied an important place in the national education. Through it, we have provided quality education in places lacking in education, bringing development to the region where the poles of presence support. Which are essential in the development of courses, the pole is where the student has the support provided by the framework available computer labs, classrooms and library - as well as classroom tutors and coordinators, who also encourage and assist in doubt that arise. This work is dedicated to analyzing the structure of all the poles supporting the project face Brazil Open University (UAB), Travel Management, Federal University of Santa Catarina. The survey was conducted based on the structure pole face minimum required by the Ministry of Education. For this purpose, a questionnaire was qualitative and quantitative in all poles, with questions directed to the purpose of this study, thus providing an overview of the structural situation of the same. It was noticed that there are structural differences between the poles of the same course and design, all of which showed any deficiency on the structure proposed by MEC.
\end{abstract}

Keywords: Distance education. Open university of Brazil. Polo to support classroom. Structure. 